\title{
Orally administered, insulin-loaded amidated pectin hydrogel beads sustain plasma concentrations of insulin in streptozotocin-diabetic rats
}

\author{
C T Musabayane ${ }^{1}$, O Munjeri ${ }^{2}$, P Bwititi $^{1}$ and E E Osim ${ }^{1}$ \\ ${ }^{1}$ Department of Physiology, University of Zimbabwe, P O Box MP167, Mount Pleasant, Harare, Zimbabwe \\ ${ }^{2}$ Department of Pharmacy, University of Zimbabwe, P O Box MP167, Mount Pleasant, Harare, Zimbabwe \\ (Requests for offprints should be addressed to C T Musabayane; Email: ctm@kidney.uz.zw or Musabayane@mango.apc.org.zw)
}

\begin{abstract}
We report successful oral administration of insulin entrapped in amidated pectin hydrogel beads in streptozotocin (STZ)-diabetic rats, with a concomitant reduction in plasma glucose concentration. The pectin-insulin (PI) beads were prepared by the gelation of humilin-pectin solutions in the presence of calcium. Separate groups of STZ-diabetic rats were orally administered two PI beads (30 $\mu \mathrm{g}$ insulin) once or twice daily or three beads $(46 \mu \mathrm{g})$ once daily for 2 weeks. Control non-diabetic and STZdiabetic rats were orally administered pectin hydrogel drug-free beads. By comparison with control non-diabetic rats, untreated STZ-diabetic rats exhibited significantly low plasma insulin concentration $(0.32 \pm 0.03 \mathrm{ng} / \mathrm{ml}$, $n=6$, compared with $2 \cdot 60 \pm 0 \cdot 44 \mathrm{ng} / \mathrm{ml}$ in controls, $n=6)$ and increased plasma glucose concentrations $(25.84 \pm 1.44 \mathrm{mmol} / 1$ compared with $10.72 \pm$ $0.52 \mathrm{mmol} / 1$ in controls). Administration of two PI beads twice daily (60 $\mu \mathrm{g}$ active insulin) or three beads $(46 \mu \mathrm{g})$
\end{abstract}

once a day to STZ-diabetic rats increased plasma insulin concentrations $(0.89 \pm 0.09 \mathrm{ng} / \mathrm{ml}$ and $1.85 \pm$ $0 \cdot 26 \mathrm{ng} / \mathrm{ml}$, respectively), with a concomitant reduction in plasma glucose concentration $(15.45 \pm 1.63 \mathrm{mmol} / \mathrm{l}$ and $10.56 \pm 0.26 \mathrm{mmol} / 1$, respectively). However, a single dose of PI beads $(30 \mu \mathrm{g})$ did not affect plasma insulin concentrations, although plasma glucose concentrations $(17.82 \pm 2.98 \mathrm{mmol} / \mathrm{l})$ were significantly reduced compared with those in untreated STZ-diabetic rats. Pharmacokinetic parameters in STZ-diabetic rats show that the orally administered PI beads ( $30 \mu \mathrm{g}$ insulin) were more effective in sustaining plasma insulin concentrations than was s.c. insulin $(30 \mu \mathrm{g})$. The data from this study suggest that this insulin-loaded amidated pectin hydrogel bead formulation not only produces sustained release of insulin, but may also reduce plasma glucose concentration in diabetes mellitus.

Journal of Endocrinology (2000) 164, 1-6

\section{Introduction}

Treatment of diabetes mellitus usually requires daily s.c. injections of insulin, which can result in non-compliance of the patient because of local discomfort caused and inconvenience of multiple administration (Van Haeften et al. 1987). The oral route is the most acceptable route of administration of insulin and may thus encourage patient compliance. However, oral administration of insulin is precluded by digestion in the stomach and small intestine (Lee et al. 1991, Zhou \& Li Wan Po 1991). Schilling \& Mitra (1990) have suggested that delivery to the mid-jejunum protects insulin from hydrolysis and that release from the dosage form is enhanced by intestinal microflora. The need to find a system for oral administration of insulin has resulted in many investigations to protect the molecule from degradation and to facilitate transepithelial transport of the intact molecule (Saffran et al. 1986, 1990).
Attempts have been made to deliver insulin to the more distal portions of the gastrointestinal tract by microencapsulation using Eudragit RS 100 (Morishita et al. 1993). Polymeric structures formed by polymerization of isobutyl cyanoacrylate (IBCA) in an acidic medium have also been used for oral administration of insulin in diabetic rats (Damge et al. 1997). However, the limitations of these formulations include the difficulty of removing organic solvents from the final product and the possibility of structural modification of the drug. Pectin (polygalacturonic acid) has been investigated for specific delivery to the colon because it is biodegradable (Ashford et al. 1993, Rubinstein et al. 1993, Munjeri et al. 1998a, b). Colonic release of insulin by a pectin-coated support has already been examined (Rubinstein et al. 1997). The purpose of the present study was to investigate the effects of oral administration of insulin-loaded amidated pectin beads on plasma insulin and plasma glucose in streptozotocin (STZ)-diabetic rats. 


\section{Materials and Methods}

\section{Chemicals}

Streptozotocin, calcium chloride, monobasic potassium phosphate, pancreatin and pepsin were obtained from Sigma Chemical Company (St Louis, MO, USA), humilin (Isophane Human Insulin manufactured by Lilly France SA, Fegershiem, France) was obtained from Eli Lilly, Pty Ltd (Isando, Guateng, Republic of South Africa). Sodium hydroxide, potassium hydroxide and chloroform were obtained from Associated Chemical Enterprises (Mulbarton, Republic of South Africa). Hydrochloric acid $(\mathrm{HCl}, 32 \% \mathrm{v} / \mathrm{v})$ was obtained from Saarchem Muldedrift (Krugersdorp, Republic of South Africa). Amidated lowmethoxyl pectin with a degree of methoxylation of 23 and degree of amidation of 24 was a donation from Citrus Colloids (Hereford, UK). The aqueous buffer system used was Sorensen's phosphate buffer ( $\mathrm{pH} 7 \cdot 4)$.

\section{Preparation of pectin-insulin hydrogel beads}

The method of hydrogel bead production was similar to that reported previously (Munjeri et al. 1997, 1998a). Pectin solutions $(4 \% \mathrm{w} / \mathrm{v})$ were prepared by dispersing the pectin powder in distilled water with the aid of a highspeed mixer. Amidated pectin-insulin (PI) hydrogel beads with specified pectin: humilin $(\mathrm{v} / \mathrm{v})$ ratios of $200: 1$, $133: 1$ and $80: 1$ were produced by dispersing insulinloaded amidated pectin solutions drop-wise into $300 \mathrm{ml}$ agitated calcium chloride $2 \%(\mathrm{w} / \mathrm{v})$ solutions. The solutions were pumped at $1.0 \mathrm{ml} / \mathrm{min}$ by a peristaltic pump (Masterflex, Barrington, IL, USA) through a tube $2 \mathrm{~mm}$ in diameter. The beads were separated and dried thoroughly in air and stored in the refrigerator until use. Insulin loading efficiencies were determined by radioimmunoassay after a specified number of beads were completely dissolved in Sorensen's phosphate buffer ( $\mathrm{pH} 7 \cdot 4)$. Preliminary studies showed that amidated pectin beads with $80: 1$ humilin loading were appropriate for using in the animals.

\section{Animal studies}

Male Sprague-Dawley rats (230-260 g body weight), bred and housed in the Medical Faculty animal house of the University of Zimbabwe, were made diabetic by an i.p. injection of STZ $60 \mathrm{mg} / \mathrm{kg}-1^{-1}$ in citrate buffer. Vehicleinjected animals acted as non-diabetic controls. Animals that exhibited glycosuria after $24 \mathrm{~h}$, tested by the combur 9 test (Boehringer) were considered diabetic. The rats were kept separately in metabolism cages (NKP, Dartford, Kent, UK) that were cleaned daily. Four groups of STZ-diabetic rats and an additional group of non-diabetic rats were used. One group was orally administered two PI beads (30 $\mu \mathrm{g}$ insulin) once daily at $0900 \mathrm{~h}$ and the second group received the same dose of PI beads at $0900 \mathrm{~h}$, followed by the same dose $8 \mathrm{~h}$ later $(1700 \mathrm{~h})$. The third group of STZ-diabetic rats was orally administered PI beads $(46 \mu \mathrm{g})$ daily for 2 weeks at $0900 \mathrm{~h}$. Untreated STZ-diabetic and control non-diabetic rats were orally administered pectin hydrogel drug-free beads. The beads were administered by means of a soft tube and complete delivery to the stomach was achieved by flushing the beads with $1 \mathrm{ml}$ water.

The rats in all groups had both food (Mouse Comproids, National Foods, Harare, Zimbabwe) and water available ad libitum; amounts consumed and body weights were measured daily for 2 weeks. Urine volumes voided and fluid and food consumption were determined at $0900 \mathrm{~h}$ each day. After 2 weeks, blood samples were collected at $0900 \mathrm{~h}$ into plain tubes (for insulin measurements) and fluoride tubes (for glucose determinations). Plasma was separated by centrifugation at 3000 r.p.m. (Sorvall RT6000 refrigerated centrifuge, Dupont, Boston, MA, USA) for $10 \mathrm{~min}$. Plasma for measurement of insulin was stored in a Bio Ultra freezer (Mallinckrodt, Ohio, USA) at $-70{ }^{\circ} \mathrm{C}$ until required for measurements of insulin by radioimmunoassay.

\section{Pharmacokinetic studies}

Separate groups of STZ-diabetic rats previously given two beads $(30 \mu \mathrm{g}$ insulin) at $0900 \mathrm{~h}$ and the same dose at $1700 \mathrm{~h}$ were used for pharmacokinetic studies. Sixteen hours after the last dose, the animals were administered either PI beads ( $30 \mu \mathrm{g}$ insulin) orally, or s.c. insulin (30 $\mu \mathrm{g})$ at $0900 \mathrm{~h}$, followed by a similar dose at $1700 \mathrm{~h}$. Blood samples were collected for insulin and glucose measurements at $0900 \mathrm{~h}, 1100 \mathrm{~h}, 1300 \mathrm{~h}, 1700 \mathrm{~h}, 1500 \mathrm{~h}$ and $2100 \mathrm{~h}$, and at $0300 \mathrm{~h}$ on the following day.

\section{Plasma glucose and serum insulin measurements}

Plasma glucose concentrations were measured by the glucose oxidase method immediately after collection using a Glucose Enzymatique Kit from bioMérieux SA (Marcyl'Etoile, France. Serum insulin concentrations were measured by Coat-A-Count procedure using a kit from Diagnostic Products Corporation (Los Angeles, CA, USA). This is a solid-phase radioimmunoassay procedure based on insulin-specific antibody immobilized to the wall of a polypropylene tube. The lower limit of detection was $55 \mathrm{pg} / \mathrm{ml}$. Inter- and intra-assay coefficients of variation were $8 \cdot 1 \%(n=20)$ and $8 \cdot 3 \%(n=20)$ respectively.

\section{Data analysis}

All data were subjected to one-way analysis of variance; Scheffé's multiple comparison test was used to resolve any apparent differences. A value of $P>0.05$ was considered significant. The time for the peak insulin plasma 
Table 1 Insulin-loading efficiencies in bead samples. Each theoretical and actual loading value represents the mean value of five different samples, with each sample containing five beads

\begin{tabular}{|c|c|c|c|c|}
\hline & $\begin{array}{l}\text { Mean mass of } \\
\text { five beads }(\mathrm{mg})\end{array}$ & $\begin{array}{l}\text { Theoretical loading } \\
\text { in five beads }(\mu \mathrm{g})\end{array}$ & $\begin{array}{l}\text { Actual loading in } \\
\text { five beads }(\mu \mathrm{g})\end{array}$ & $\begin{array}{l}\text { Loading } \\
\text { efficiency (\%) }\end{array}$ \\
\hline \multicolumn{5}{|l|}{ PI ratio $†$} \\
\hline $200: 1$ & $18 \cdot 68 \pm 0 \cdot 19$ & 39 & $33 \pm 3$ & 85 \\
\hline $133: 1$ & $19 \cdot 88 \pm 0 \cdot 20$ & 62 & $53 \pm 7$ & 85 \\
\hline $80: 1$ & $19 \cdot 44 \pm 0 \cdot 26$ & 101 & $75 \pm 7$ & 74 \\
\hline
\end{tabular}

†Ratio of PI in $100 \mathrm{ml}$ solution used to make beads.

concentration $\left(T_{\mathrm{p}}\right)$ and the maximum plasma insulin concentrations $\left(C_{\max }\right)$ were obtained from the graph. The area under the curve up to the last sampling time after the oral dose or s.c. insulin injection was calculated by the trapezoidal rule. The remaining area was calculated using the formula $\mathrm{Cx} / \mathrm{kel}$ ( $\mathrm{Cx}$ being the last plasma concentration determined and kel the slope of the terminal part of the graph). The loading efficiency of the beads was calculated by dividing the actual insulin content in the beads by the theoretical content and expressed as a percentage.

\section{Results}

Insulin-loading efficiency in the pectin hydrogel beads

The loading efficiency of insulin in beads ranged from 74 to $85 \%$ (Table 1) and each bead made from the solution with a pectin: insulin ratio of $80: 1$ contained $15 \mu \mathrm{g}$ insulin. A minimum dose of $30 \mu \mathrm{g}$ insulin was selected for the in vivo studies and compares to doses previously used in other studies (Shaw \& Su 1991, Sai et al. 1996).

Water and electrolyte turnover in 2 weeks

Table 2 compares $24 \mathrm{~h}$ food intake, daily weight changes and volumes of urine voided by control non-diabetic and STZ-diabetic rats and treated STZ-diabetic rats. Untreated non-diabetic rats progressively gained weight, whereas STZ-diabetic animals lost weight throughout the 10-day period, before gaining between 12 and 14 days. The total amount of food consumed by non-diabetic and untreated STZ-diabetic rats did not differ significantly. However, daily oral administration of PI beads reduced the amount of food consumed between days 6 and 10, before returning to values comparable to those in untreated non-diabetic and diabetic rats during days 12 and 14 . Untreated STZ-diabetic animals consumed more water throughout the 2-week period compared with other groups. The water intake by treated diabetic rats did not

Table 2 Comparison of body weight and 14-day measures of food and water taken and fluid voided in untreated non-diabetic and STZ-diabetic rats, and in STZ-diabetic rats administered PI beads (30 $\mu \mathrm{g}$ insulin) twice daily over 14 days (treated). $n=6$ in all groups

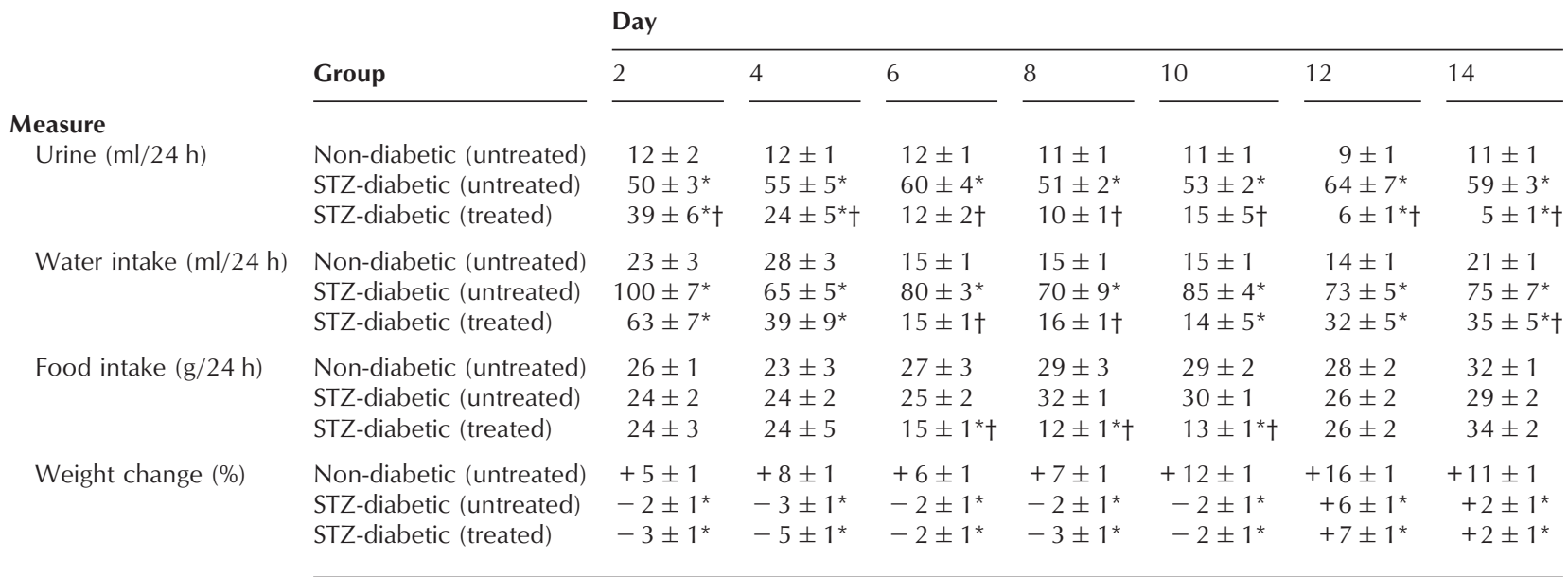

${ }^{*} P<0.05$ compared with non-diabetic rats; $+P<0 \cdot 05$ compared with respective STZ-diabetic untreated rats. 


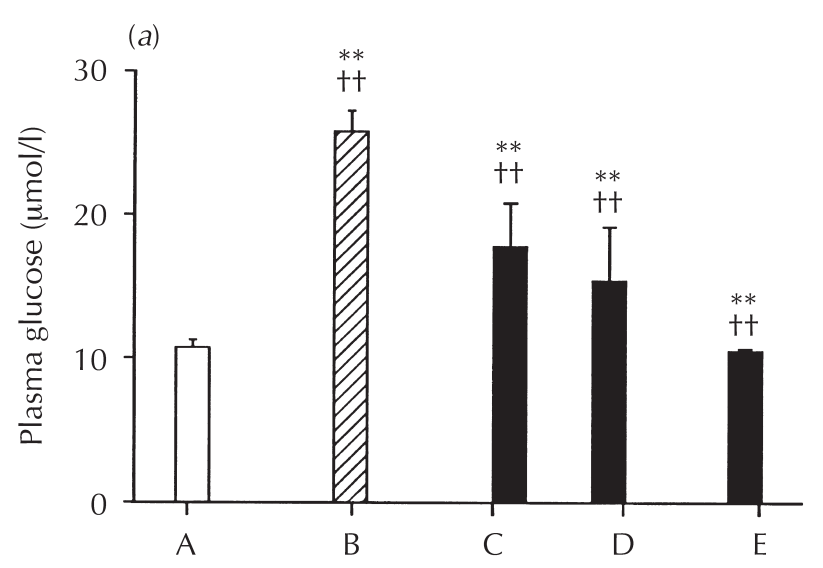

(b)

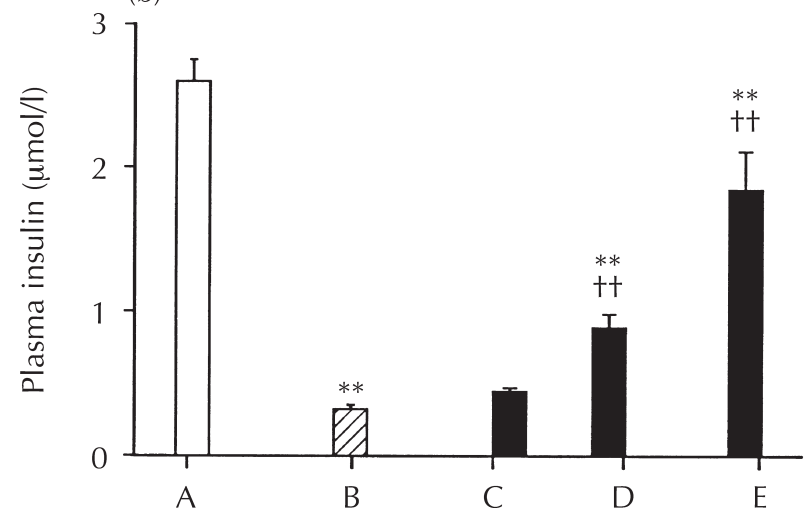

Figure 1 Comparison of plasma glucose (a) and plasma insulin (b) concentrations in control (untreated) non-diabetic rats $(A, \square$, $n=6)$ and STZ-diabetic rats (B, cross-hatched bars; $n=6)$, and separate groups ( $n=6$ each) of treated STZ-diabetic rats $(\boldsymbol{\square})$ orally administered $\mathrm{PI}$ beads delivering active insulin $30 \mu \mathrm{g}$ once $(\mathrm{C})$ or twice (D) daily, or $46 \mu \mathrm{g}$ once daily (E) for 14 days. $P<0 \cdot 01$ compared with: **non-diabetic control rats and ††untreated STZ-diabetic rats.

significantly differ from that of non-diabetic rats between days 6 and 10, although more water was taken during days 2-4 and days 12-14. Administration of PI beads significantly reduced the amount of water taken by the groups concerned throughout the 14-day period, compared with the amounts taken by untreated STZ-diabetic rats.

\section{Plasma insulin and glucose concentrations}

When compared with control non-diabetic rats, untreated STZ-diabetic rats exhibited significantly low plasma insulin concentrations $(0.32 \pm 0.03 \mathrm{ng} / \mathrm{ml}$, compared with $2.60 \pm 0.44 \mathrm{ng} / \mathrm{ml}, n=6$ in both groups) and increased plasma glucose concentrations $(25.84 \pm 1.44 \mathrm{mmol} / \mathrm{l}$ compared with $10 \cdot 72 \pm 0.52 \mathrm{mmol} / \mathrm{l}$ ) after 2 weeks (Fig. 1). Daily oral administration of PI beads once $(30 \mu \mathrm{g}$ insulin) resulted in a slight, but statistically insignificant increase in plasma insulin concentrations $(0.45 \pm 0.02 \mathrm{ng} /$ $\mathrm{ml}$ ) by comparison with untreated STZ-diabetic rats. However, this treatment was associated with a significant $(P>0 \cdot 01)$ reduction in plasma glucose concentrations $(17.82 \pm 2.98 \mathrm{mmol} / \mathrm{l})$ in comparison with values in untreated STZ-diabetic rats. Administration, at $0900 \mathrm{~h}$ for 2 weeks, of two PI beads containing $30 \mu \mathrm{g}$ active insulin twice daily and three PI beads once daily ( $46 \mu \mathrm{g}$ active insulin) to STZ-diabetic rats increased plasma insulin concentrations $(0.89 \pm 0.09 \mathrm{ng} / \mathrm{ml}$ and $1.85 \pm 0.26 \mathrm{ng} / \mathrm{ml}$ respectively), with a concomitant reduction in plasma glucose concentration $(15.45 \pm 1.63 \mathrm{mmol} / \mathrm{ml}$ and $10.56 \pm$ $0 \cdot 26 \mathrm{mmol} / \mathrm{ml}$ respectively) at $0900 \mathrm{~h}$ the next day.

\section{Pharmacokinetic parameters}

STZ-diabetic rats previously given two oral doses daily of two PI beads ( $30 \mu \mathrm{g}$ insulin) at $0900 \mathrm{~h}$ and the same dose $8 \mathrm{~h}$ later $(1700 \mathrm{~h})$ were used for pharmacokinetic studies $16 \mathrm{~h}$ after the last dose, at $0900 \mathrm{~h}$ the next day. The plasma insulin concentration-time profiles and the pharmacokinetic parameters after the oral administration of PI beads $(30 \mu \mathrm{g}$ insulin) or s.c. insulin $(30 \mu \mathrm{g})$ at $0900 \mathrm{~h}$ and similar doses $8 \mathrm{~h}$ later $(1700 \mathrm{~h})$ are shown in Fig. 2 and Table 3 respectively. The mean $C_{\max }$ plasma insulin concentration value was achieved earlier when PI beads were administered, compared with results after s.c. insulin (Fig. 2). Plasma glucose concentrations in animals orally administered PI beads decreased significantly from the 2 nd hour before increasing again before the second treatment (Fig. 2). However, significant decreases in plasma glucose after s.c. insulin were observed only after $6 \mathrm{~h}$, whereas plasma glucose concentrations were always significantly greater between $1100 \mathrm{~h}$ and $1500 \mathrm{~h}$ compared with values in STZdiabetic rats orally administered PI beads.

\section{Discussion}

In the present study, successful delivery of insulin from orally administered, insulin-loaded, amidated pectin hydrogel beads in STZ-diabetic rats was achieved, as assessed by increases in plasma insulin concentrations and associated reductions in plasma glucose concentrations. As the STZ used to induce diabetes selectively destroys or impairs insulin secretion by $\beta$ cells of the pancreas (Grussner et al. 1993), low plasma insulin concentrations found in untreated STZ-diabetic rats may be attributed to residual $\beta$ cells of the pancreas. We prepared the insulin hydrogel beads by the gelation of a humilin (human insulin)-loaded pectin solution, as there is no difference in biological potency of human insulin and animal insulins (Brogden \& Heel 1987, Heinemann \& Ritcher 1993). Studies have shown that s.c. administration of humilin reduces blood glucose in rats (Shaw \& Su 1991) and non-obese mice (Sai et al. 1996). The doses of insulin $(0 \cdot 10 \mu \mathrm{g} / \mathrm{kg}$ once or twice, 


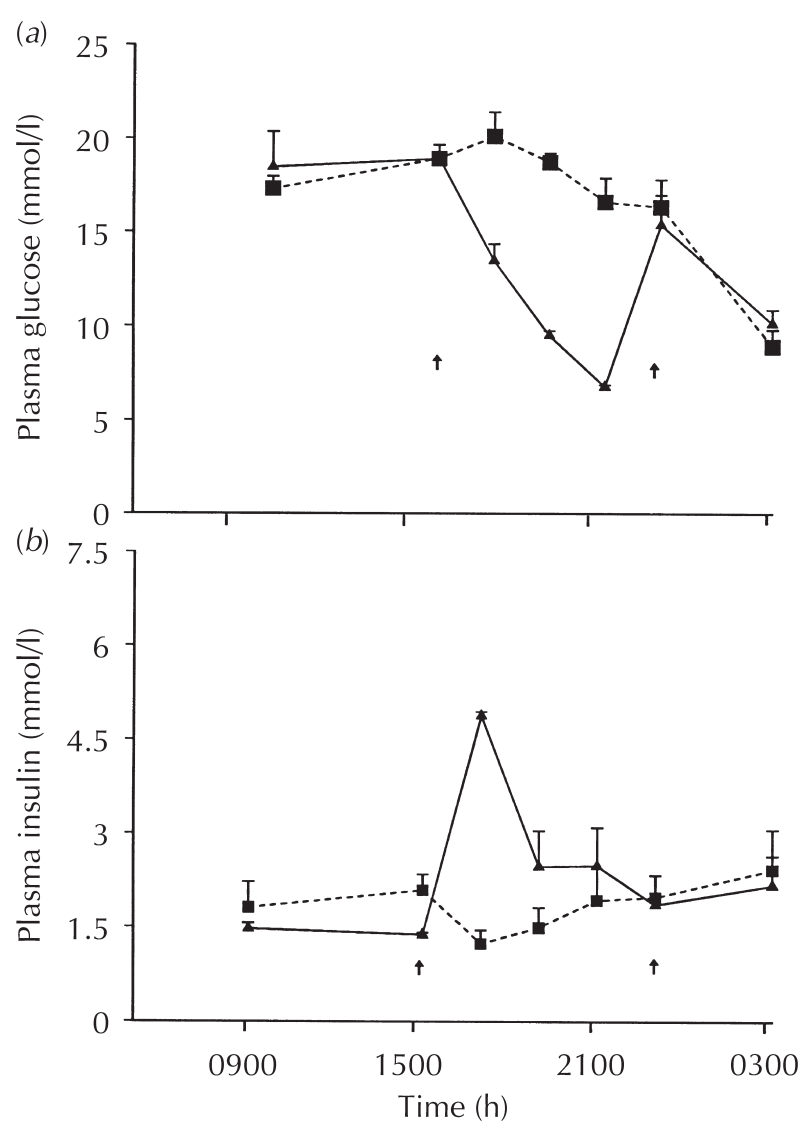

Figure 2 Comparison of the effects of oral administration of Pl beads (30 $\mu \mathrm{g}$ insulin; $\boldsymbol{\Delta})$ and s.c. insulin $(30 \mu \mathrm{g} ; \boldsymbol{\square})$ at $0900 \mathrm{~h}$ and $1700 \mathrm{~h}$ on plasma glucose (a) and plasma insulin (b) concentration profiles in STZ-diabetic rats previously orally administered PI beads (30 $\mu \mathrm{g}$ insulin) twice daily for 14 days. Arrows indicate times of dosing. Each point represents the mean \pm S.E.M. of six animals.

and $0 \cdot 15 \mu \mathrm{g} / \mathrm{kg}$ once) chosen in this study are lower than those previously used in human studies $(6 \cdot 25-17 \cdot 86 \mu \mathrm{g} / \mathrm{kg}$; Peacey et al. 1999, Simpson \& Spencer 1999).

Previous observations suggest that insulin absorption in the intestinal tract occurs in the ileum, large intestine and the jejunum (Kimura et al. 1996). The appearance of significant plasma concentrations of insulin $2-4 \mathrm{~h}$ after oral administration of PI beads, with a decrease in plasma glucose concentrations, in STZ-diabetic rats suggests

Table 3 Pharmacokinetic parameters after oral administration of PI beads $(30 \mu \mathrm{g}$ insulin) and s.c. insulin $(30 \mu \mathrm{g})$ to male Sprague-Dawley rats

\begin{tabular}{|c|c|c|c|}
\hline & $\begin{array}{l}C_{\max } \\
(\mathrm{mmol} / \mathrm{l})\end{array}$ & $\begin{array}{l}\boldsymbol{T}_{\mathbf{p}} \\
(\mathrm{h})\end{array}$ & $\begin{array}{l}\text { AUC } \\
(\mathrm{mmol} / \mathrm{l} \text { per } \mathrm{h})\end{array}$ \\
\hline \multicolumn{4}{|l|}{ Dosage form } \\
\hline Oral PI beads $(30 \mu \mathrm{g})$ & $4 \cdot 88 \pm 0.06$ & 2 & $39 \cdot 51$ \\
\hline S.c. insulin $(30 \mu \mathrm{g})$ & $2 \cdot 42 \pm 0 \cdot 22$ & 18 & $33 \cdot 89$ \\
\hline
\end{tabular}

release of insulin from the beads and its intestinal absorption in these regions. This not only coincides with transit time in the rat, but agrees with observations of peak plasma insulin concentrations and hypoglycaemic effects within $1.5-2 \mathrm{~h}$ after oral administration of insulin coated with polymers cross-linked with azoaromatic groups, to rats and diabetic dogs (Saffran et al. 1986, 1991). Conceivably, insulin released will have some contact with luminal contents before absorption, and thus luminal proteolysis by microbial proteases has to be reduced. The present study did not investigate the influence of protease inhibitors, absorption enhancers and polymeric coatings, which can significantly improve bioavalability. However, carbopol polymers have been used to reduce the colonic proteolysis of insulin, enhancing pharmacological effects of the peptide in rats (Bai et al. 1995).

The present findings cannot explain why administration of PI beads delivering a single $46 \mu \mathrm{g}$ dosage of insulin appears to be more efficient than the two doses delivering $30 \mu \mathrm{g}$ given at $0900 \mathrm{~h}$ and $1700 \mathrm{~h}$. Perhaps the transit time of individual beads and enzymatic breakdown of the beads and the influence of food contributed to these observations. Interestingly, Saffran et al. (1991) also could not find dose-related changes in plasma insulin concentrations after oral administration of various doses of insulin in azopolymer-coated capsules.

The pharmacokinetic parameters after oral dosing and s.c. injections suggest that $C_{\max }$ plasma insulin concentration is attained sooner when the oral route is used (Fig. 2, Table 3). If insulin were released from the PI beads in the distal parts of the intestine, then the mean $C_{\max }$ plasma insulin concentration should be reached much later by comparison with s.c. insulin. We suggest that insulin was initially released as a bolus, as a result of solubilization of pectin gels by excess hydroxyl ions (Munjeri et al. 1997), and also because of increases in electrostatic repulsions between pectin molecules resulting from hypo-osmotic conditions (Cunha et al. 1997). The release of insulin from pectin hydrogel beads is also enhanced by the breakdown of pectin by colonic bacteria. The decrease in plasma glucose concentrations $6 \mathrm{~h}$ after s.c. injection of humilin agrees with previous observations (Berger \& Rodbard 1998).

Food consumption was reduced in STZ-diabetic rats between 6 and 10 days after they received PI beads. This observation cannot be explained by the results from the present study, but may be related to the stage of diabetes development when insulin may modulate food intake. A reduction in food intake has been reported after intraventricular infusion of insulin in Zucker rats (Ikeda et al. 1986, Alemzadeh \& Holshouser 1999). The presence of insulin receptors on the luminal side of the intestinal mucosa (Pillion et al. 1985) suggests that insulin may modulate intestinal function in some way.

In conclusion, data from this study suggest that an insulin-loaded, amidated pectin hydrogel bead formulation 
not only produces sustained release of insulin, but may also reduce plasma glucose concentration in diabetes mellitus.

\section{Acknowledgements}

Professor C T Musabayane was funded by the University of Zimbabwe Research Board (YYH010/3580). The authors are grateful for the technical support from Messrs P Hodza, A Musvibe and J Wenyika.

\section{References}

Alemzadeh R \& Holshouser S 1999 Effect of diazoxide on brain capillary insulin receptor binding and food intake in hyperphagic obese Zucker rats. Endocrinology 40 3197-3202.

Ashford M, Fell JT, Attwood D, Sharma H \& Woodhead P 1993 An evaluation of pectin as a carrier for drug targeting to the colon. Journal of Controlled Release 26 330-331.

Bai JPF, Chang LL \& Guo JH 1995 Effects of polyacrylic polymers on the lumenal proteolysis of peptide drugs in the colon. Journal of Pharmaceutical Sciences 84 1291-1294.

Berger M \& Rodhard D 1998 Computer simulation of plasma insulin and glucose dynamics after subcutaneous injections. Diabetes Care $12725-736$

Brogden RN \& Heel RC 1987 Human insulin: a review of its biological activity, pharmacokinetics and therapeutic use. Drugs 34 350-357.

Cunha AS, Grossiord JL, Puisieux F \& Seiller M 1997 Insulin in w/o/w multiple emulsions: biological activity after oral administration in normal and diabetic rats. Journal of Microencapsulation 14 321-333.

Damge C, Vranckx H, Balschmidt P \& Couvreur P 1997 Poly(alkyl) nanospheres for oral administration of insulin. Journal of Pharmaceutical Sciences 86 1403-1409.

Grussner R, Nakhleh R, Grussner A, Tomadze G, Diem P \& Sutherland D 1993 Streptozotocin-induced diabetes in pigs. Hormone Metabolism Research 25 199-203.

Heinemann L \& Ritcher RC 1993 Clinical pharmacology of human insulin. Diabetes Care 16 90-100.

Ikeda H, West DB, Putsek JJ, Figlewicz DP, Greenwood MR, Porte D Jr \& Woods SC 1986 Intraventricular insulin reduces food intake and body weight of lean but not obese Zucker rats. Appetite 7 381-386.

Kimura T, Sato K, Sugimoto K, Tao R, Murakami T, Kurosaki Y \& Nakayama T 1996 Oral administration of insulin as poly(vinyl alcohol)-gel spheres in diabetic rats. Biological and Pharmaceutical Bulletin 19 897-900.

Lee VHL, Dodda-Kashi S, Grass GM \& Rubas W 1991 Oral route of peptides and protein drug delivery. In Peptide and Protein Drug Delivery, pp 691-738. Ed VHL Lee. New York: Dekker.

Morishita I, Morishita M, Takayama K, Machida Y \& Nagai T 1993 Enteral insulin delivery by microspheres in 3 different formulations using Eudragit L100 and S100. International Journal of Pharmaceutics 91 23-37.
Munjeri O, Collett JH \& Fell JT 1997 Hydrogel beads based on amidated pectins for colon-specific drug delivery: the role of chitosan in modifying drug release. Journal of Controlled Release 46 273-278.

Munjeri O, Collett JH, Fell JT, Sharma HL \& Smith A-M 1998a In vivo behavior of hydrogel beads based on amidated pectins. Drug Delivery 5 239-241.

Munjeri O, Hodza P, Osim EE \& Musabayane CT 1998b An investigation into the suitability of amidated pectin hydrogel beads as a delivery matrix for chloroquine. Journal of Pharmaceutical Sciences 87 905-908.

Peacey SR, Rostami-Hodjegan A, George E, Tucker GT \& Heller SR 1999 The use of tolbutamide-induced hypoglycaemia to examine the intraislet role of insulin in mediating glucagon release in normal humans. Journal of Clinical Endocrinology and Metabolism 82 $1458-1461$

Pillion DJ, Ganapathy V \& Liebach FH 1985 Identification of insulin receptors on the mucosal surface of colon epithelial cells. Journal of Biological Chemistry $2605244-5247$.

Rubinstein A, Radai R, Ezra M, Pathak S \& Rokem JS 1993 in vitro evaluation of calcium pectinate: a potential colon-specific drug delivery carrier. Pharmaceutical Research 10 258-263.

Rubinstein A, Radai R, Friedman M, Fischer P \& Rokem JS 1997 The effect of intestinal bacteria adherence on drug diffusion through solid films under stationary conditions. Pharmaceutical Research 14 503-507.

Saffran M, Kumar GS, Savariar C, Burnham JC, Williams F \& Neckers DC 1986 A new approach to the oral administration of insulin and other peptide drugs. Science 233 1081-1084.

Saffran M, Kumar GS, Neckers DC, Pena J, Jones RH \& Field JBS 1990 Biodegradable azopolymer coating for oral delivery of peptide drugs. Biochemical Society Transactions 18 752-752.

Saffran M, Field JBS, Pena J, Jones RH \& Okuda Y 1991 Oral insulin in diabetic dogs. Journal of Endocrinology 131 267-278.

Sai P, Damage C, Rivereau AS, Hoeltzel A \& Gouin E 1996 Prophylactic oral administration of metabolically active insulin entrapped in isobutylcyanoacrylate nanocapsules reduces the incidence of diabetes in nonobese diabetic mice. Journal of Autoimmunity 9 713-722.

Schilling RJ \& Mitra AK 1990 Intestinal mucosal transport of insulin. International Journal of Pharmaceutics 62 53-64.

Shaw WN \& Su KSE 1991 Biological aspects of a new human insulin analog: [lys(28), Pro(B29)]-human insulin. Diabetes 40464.

Simpson KL \& Spencer CM 1999 Insulin aspart. Drugs 57 759-765.

Van Haeften TW, Heiling VJ \& Gerich JE 1987 Adverse effects of insulin antibodies on postprandial plasma glucose and insulin profiles in diabetic patients without immune insulin resistance: implications for intensive insulin regiments. Diabetes 36 305-309.

Zhou XH \& Li Wan Po A 1991 Peptide and protein drugs: II. Non-parenteral routes of delivery. International Journal of Pharmacentics 75 117-130.

Received 12 April 1999

Accepted 11 August 1999 